\title{
Capture efficiency measurement of pollutants over a workbench with the reinforced slot exhaust system
}

\author{
O. Pech ${ }^{1, \mathrm{a}}$, and M. Pavelek ${ }^{1}$ \\ ${ }^{1}$ Brno University of Technology, Brno, Czech Republic
}

\begin{abstract}
The paper deals with the measurement of the capture efficiency of pollutants by the slot reinforced exhaust system situated in two positions over the workbench. The slot reinforced exhaust system, which is known as REEXS, is the traditional slot exhaust hood equipped with an air supply inlet that intensifies exhausting along the axis of the exhaust hood. It can operate in traditional or reinforced exhaust modes. Measurements were made for the same air velocity in the suction slot and with the different momentum flux ratio of supplied and exhausted air flow. The tracer gas method was used for the capture efficiency measurement of the system. As the tracer gas the carbon dioxide was chosen. The knowledge of the shape and range of the effective exhaust area for various configurations in front of the exhaust hood is important for the exhaust hood setting according to a source of pollutants.
\end{abstract}

\section{Introduction}

In the industrial production various pollutants are generated from technologies. These pollutants are predominantly unhealthy and their concentration in the working area must be as low as possible. To reduce the concentration of pollutants in the working area, the ventilation systems are usually used. The ventilation systems can be sort as general and local. The general ventilation systems control the concentration of pollutants in the ventilated space by means of diluting the pollution with fresh air supply. On the other hand the local exhaust systems are used to extract the polluted air from the location of its source which decreases the load of pollutants in the ventilated space, and simultaneously decreases demands to general ventilation.

The exhaust system can be sort as traditional and reinforced. The traditional exhaust system is equipped by the traditional exhaust hood. In this case the air flows in the direction to the exhaust opening evenly from all the sides but the capture efficiency of pollutants rapidly decreases with an increasing distance from the source of pollutants. Therefore the traditional exhaust hood has to be located as close to the source of pollutants as possible which is not always technically or technologically practicable. The Reinforced Exhaust System known as REEXS [1] has traditional exhaust hood equipped with an air supply inlet that intensifies exhausting along the axis of the exhaust hood. The slot reinforced exhaust hood situated over the workbench is shown in figure 1. With the suitable momentum flux ratio of supplied and exhausted air flows, the shape and the range of the effective exhaust area are possible to be partially changed and better results of the exhaustion can be reached. The position of exhaust hood over the workbench has also a significant influence on the effective exhaust area.

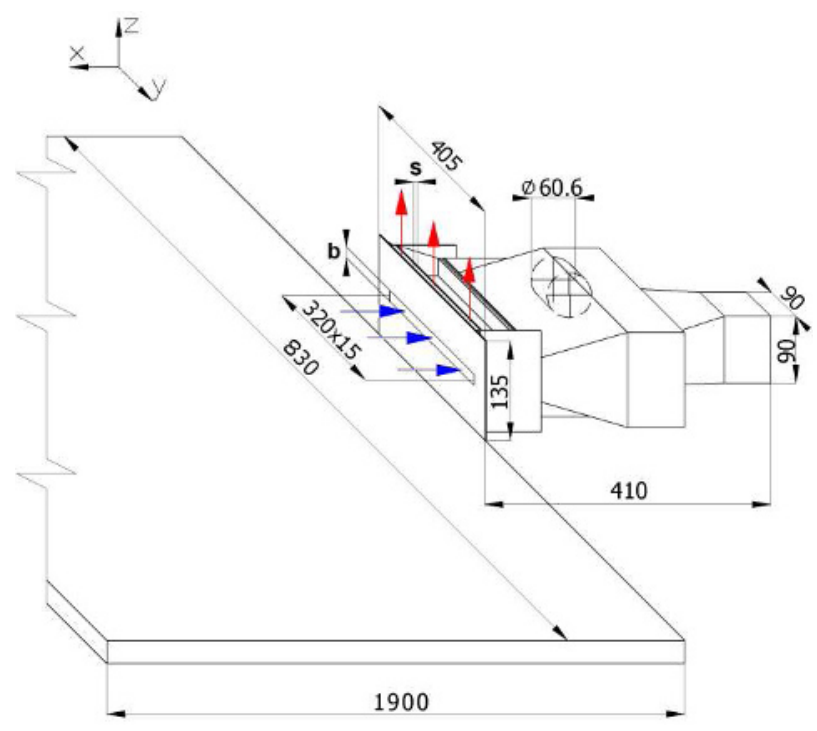

Fig. 1. Slot reinforced exhaust hood with workbench in the level of bottom edge of the flange

\section{Experimental setup}

In the research the slot reinforced exhaust hood (figure 1), designed at the Department of Thermodynamics and Environmental Engineering, Brno

\footnotetext{
aypecho01@stud.fme.vutbr.cz
} 
University of Technology, was used. The reinforced exhaust hood has one slot exhaust opening with width $b$ of $15 \mathrm{~mm}$ and a special flange with two supply slots on its long side edges. The width $s$ of supply slots can by adjusted from $1 \mathrm{~mm}$ to $8 \mathrm{~mm}$, and when measuring with the workbench the lower supply slot is blocked. This exhaust hood enables working in different modes which depends on the operating parameter $I$ (the ratio between the momentum flux supplied and the exhausted air flow). The operating parameter [2] can be determined as follows,

$$
I=\frac{\dot{m}_{s} \cdot w_{s}}{\dot{m}_{e x} \cdot w_{e x}}
$$

where $\dot{m}_{s}$ and $\dot{m}_{e x}$ represent the mass flow of the supply air and the mass flow of exhaust air, respectively, $w_{s}$ and $w_{e x}$ are velocities of the supply air and the exhaust air in the slot openings, respectively. When the operating parameter is set to $I=0$, it works as the traditional exhaust hood. In the case of nonzero value of the operating parameter, it works as the reinforced exhaust hood. It was shown that the higher the momentum fluxes ratio the higher the suction effect of the hood [3].

The measuring setup (figure 2) consists of three main parts: exhausting, air supplying and tracer gas supplying part. The exhausting duct is connected to the exhaust hood (position 1 in figure 2) and then continues with the whirler (position 2) which purpose is homogenizing the tracer gas exhausted together with the air. The whirler is followed by the flow meter (position 4) and the box equipped with two ventilators (position 5). The air supplying part has box with one ventilator (position 8) followed by the flow meter (position 7), that is connected to the exhaust hood. As a source of the tracer gas the pressure cylinder (position 9) connected to the flow meter (position 10) is used and its mouth is ended by the small porous ball (an omnidirectional pollution source, position 12). For measuring of the concentration of the tracer gas in the background and in the exhausting duct the multi gas monitor (position 16) with the multipoint sampler (position 15) are used. The measuring setup includes measurements of pressures and temperatures in the duct in front of the flow meters. Also the barometric pressure and temperatures in the air supplying slot, in the pipe in front of the porous ball for supplying tracer gas and ambient temperature are measured.

The ventilators (position 5 and 8 ) are controlled by the program with PI regulators from the computer through the communication module (position 23) and the analogue output module (position 25) connected to the triac regulators (position 26).

\section{Capture efficiency measurements}

The capture efficiency of the exhaust hood was investigated for the traditional exhaust mode $(I=0)$, and the reinforced exhaust modes $(I=0.3,0.6$, and 0.9$)$. There were used two position of the workbench with respect to the exhaust hood. In first position the workbench was situated on the bottom edge of the flange and in the second position the workbench was situated on the bottom edge of the exhaust slot opening. In both the positions the width of supplying slot opening was set to $s=4 \mathrm{~mm}$. The velocity magnitude in the exhaust slot opening was chosen to $w_{e x}=8.0 \mathrm{~m} \mathrm{~s}^{-1}$ according to the literature [4].

For the capture efficiency measurement of the reinforced exhaust system the tracer gas method was used. As a tracer gas the carbon dioxide $\left(\mathrm{CO}_{2}\right)$ was used. The tracer gas was supplied to the selected place in front of the exhaust hood by the small porous ball with the diameter of the $30 \mathrm{~mm}$ which simulates an omnidirectional pollution source [5]. The porous ball

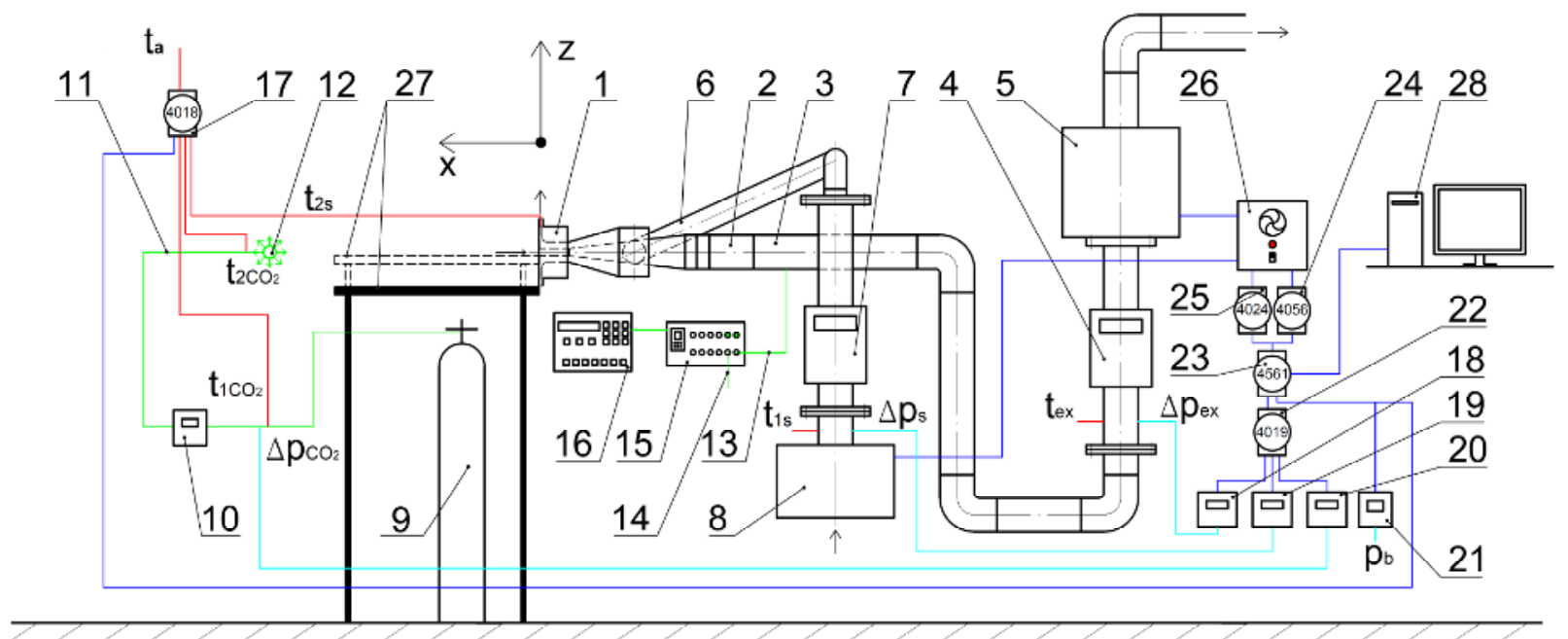

Fig. 2. Scheme of the measuring setup with the workbench in two positions against the exhaust hood

1 - reinforced exhaust hood, 2 - whirler, 3 - section for measuring concentrations, 4 - exhaust air flow meter, 5 - exhaust ventilators,

6 - supply air duct, 7 - supply air flow meter, 8 - supply air ventilator, 9 - pressure cylinder with tracer gas, 10 - tracer gas flow meter,

11 - tracer gas intake pipe, 12 - porous ball (an omnidirectional pollution source), 13, 14 - teflon tubes for gas sampling,

15 - multipoint sampler, 16 - multi gas monitor, 17 - temperature measuring module, 18 - exhaust air pressure transmitter,

19 - tracer gas pressure transmitter, 20 - supply air pressure transmitter, 21 - barometric pressure transmitter, 22 - converting module, 23 - communication module, 24 - relay output module, 25 - analogue output module, 26 - triac regulators,

27 - two positions of the workbench, $28-\mathrm{PC}$ 
1A)

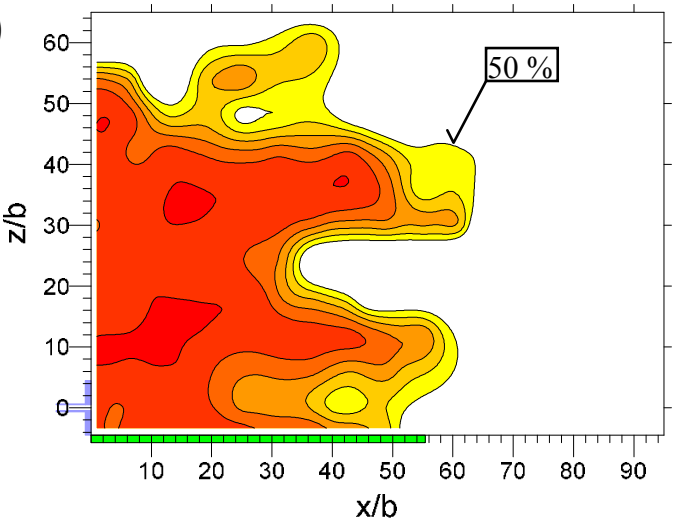

1B)

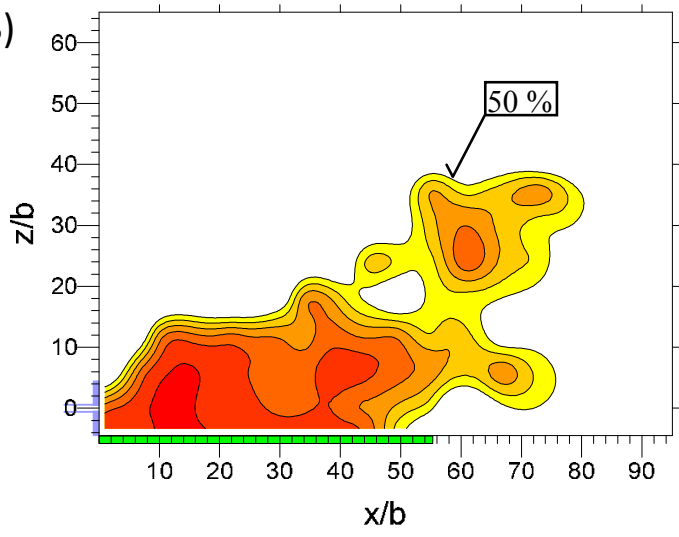

1C)

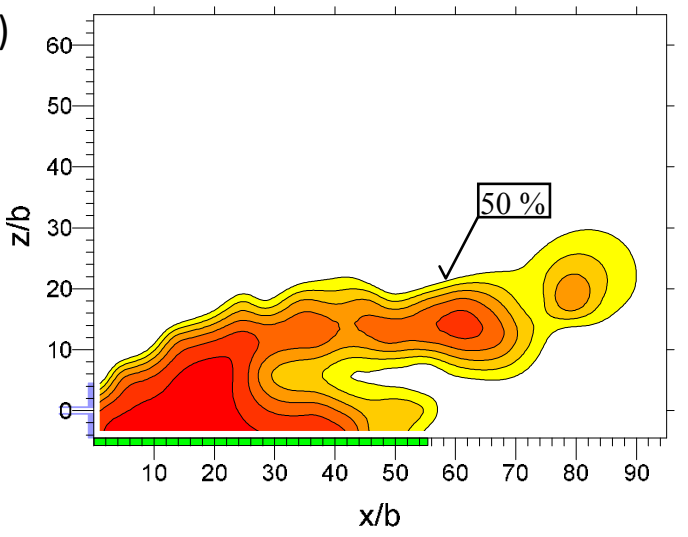

1D)

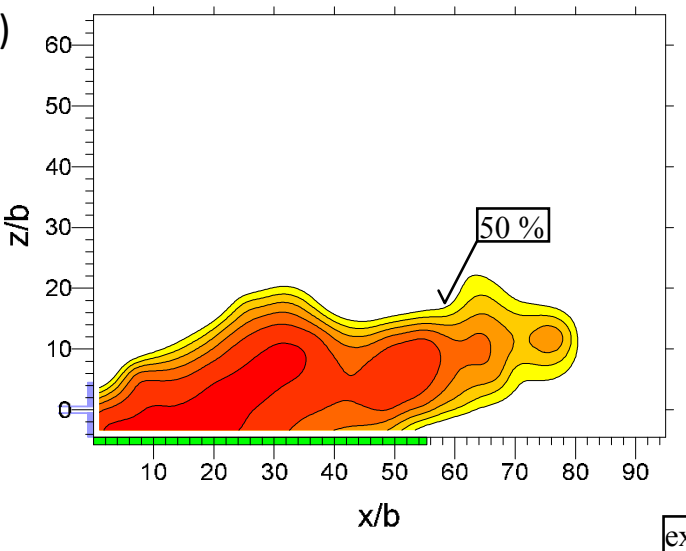

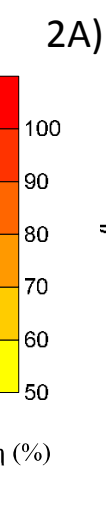
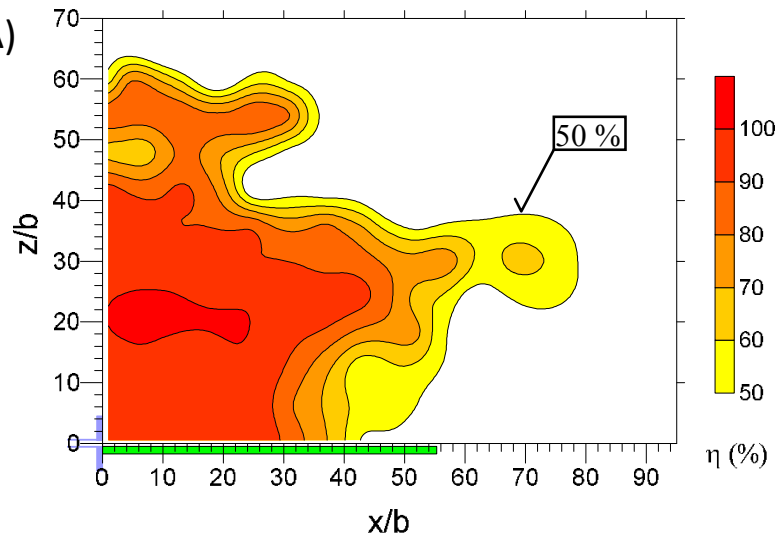

2B)
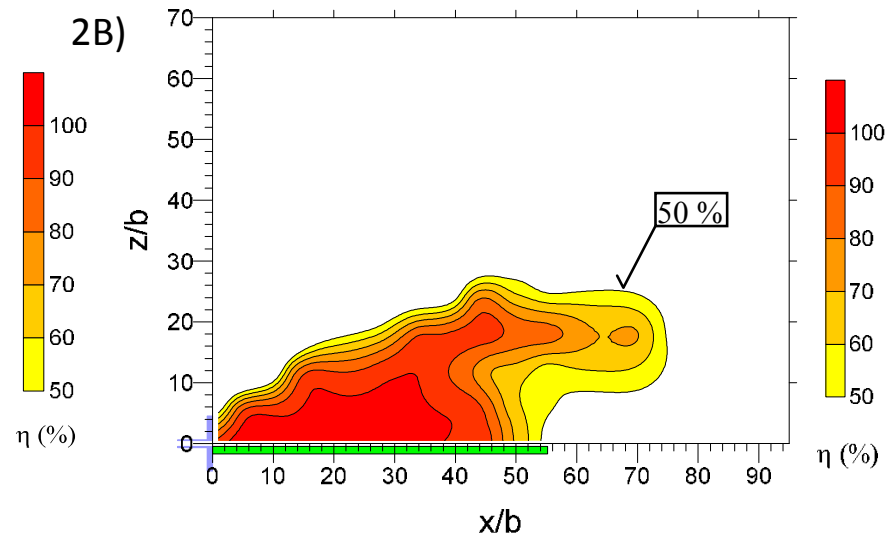

2C)
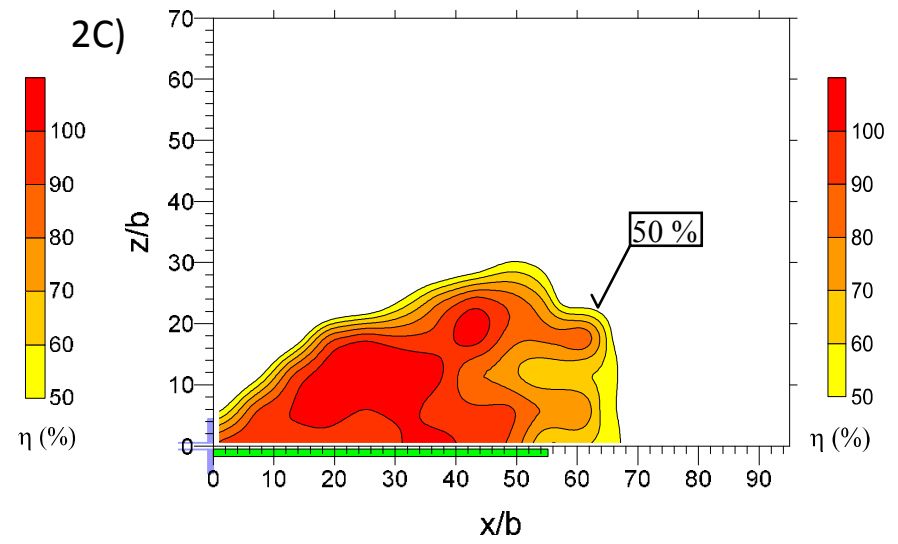

2D)
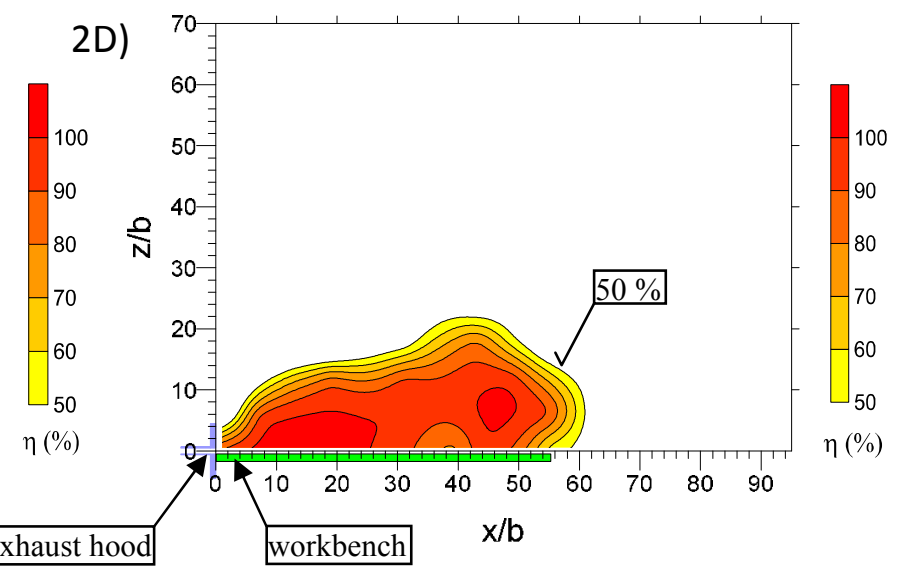

Fig. 3. Capture efficiency in the central vertical plane running through the plane $x-z$ of the slot reinforced exhaust hood 1 - exhaust hood situated over the workbench in the level of the bottom edge of the flange with operating parameter A) $I=0$; B) $I=0.3$; C) $I=0.6$; D) $I=0.9$

2 - exhaust hood situated over the workbench in the level of the bottom edge of the exhaust opening with operating parameter A) $I=0$; B) $I=0.3$; C) $I=0.6$; D) $I=0.9$ 
moves in the selected grid in the vertical plane $(x-z)$ running through the axis of the exhaust hood located in the cartesian coordinates system $(x, y, z)$. Its origin was placed to the midpoint of the exhaust slot opening of the reinforced exhaust hood. The distance between measuring points of the grid in the $x$ axis was between $45 \mathrm{~mm}$ and $90 \mathrm{~mm}$, and in $z$ axis of $90 \mathrm{~mm}$. In every point of the grid the air samples were taken from the exhaust duct behind the whirler (position 2 in figure 2) and from the background, and the concentrations are analyzed by the multi gas monitor. Then the capture efficiency of the exhaust hood from the given place in the area can be determined by

$$
\eta=\frac{C_{e x}-C_{b a c k}}{C_{r e f}},
$$

where $C_{e x}$ and $C_{b a c k}$ represent the concentration of the tracer gas in the exhaust air and in the background, respectively, and $C_{r e f}$ is the reference concentration which corresponds to the absolute capture of the supplied tracer gas.

\section{Results and discussion}

Figure 3 illustrates the essential difference in the shape of the capture effective areas of the reinforced slot exhaust hood situated in two positions over the workbench and in the different exhaust modes $(I=0, I=0.3, I=0.6$ and $I=0.9)$. The capture effective area is defined as the distance where the capture efficiency drops under the level of $50 \%$. Graphs are made in the dimensionless coordinates related to the width of exhaust slot opening of $b=15 \mathrm{~mm}$. The isolines going through the average of measured points with the step $10 \%$ are made in the graphs.

In the cases of exhausting with the operating parameter $I=0$ (diagrams $1 \mathrm{~A}$ and $2 \mathrm{~A}$ in figure 3 ), the capture effective area is much higher but the area of high capture efficiency (greater than 80\%) is along the workbench shorter in a comparison to other settings of operating parameter $I$ (cases of diagrams $1 \mathrm{~B}, 2 \mathrm{~B}, 1 \mathrm{C}, 2 \mathrm{C}$, $1 \mathrm{D}$ and $2 \mathrm{D})$. With increasing the value of operating parameter $I$, the capture effective area comes near to the board of workbench and becomes longer with the compact shape. The height of the effective capture area is smaller in the reinforced modes $(I>0)$ in the comparison to the traditional exhausting mode $(I=0)$ because in the traditional mode the pollutants are exhausted evenly from all the sides in front of the hood. But in the reinforced mode the pollutants are exhausted mainly from the narrow effective area in front of the hood. Outside of the effective area, only a small part of pollutants is exhausted, and the rest of pollutants is mixed together with the background air. This mixing is caused by the supplying air which blows away the air with pollutants and mixes it with the background air.

The capture effective area is at least as long as the workbench which is mainly caused by the significant difference between the density of used tracer gas $\left(\mathrm{CO}_{2}\right)$ and the density of air. The tracer gas falling down is partially stopped by the workbench and then partially exhausted by the exhaust hood. With increasing the distance of measuring points from the exhaust hood (axis $x$ ) and from the workbench board (axis $z$ ), not all the falling tracer gas is stopped by the workbench and then partially exhausted by the exhaust hood. It is because of the tracer gas could be carried a side by the developed flow in the room.

In the case with the workbench in the level of the bottom edge of the exhaust opening (diagrams 2A, 2B, $2 \mathrm{C}, 2 \mathrm{D}$ in figure 3.) the capture effective area has compact shape in comparison to the case with the workbench in the level of bottom edge of the flange (diagrams 1A, 1B, 1C, 1D in figure 3.). This difference is caused by the attached flow to the board of the workbench in the case with the workbench in the level of the bottom edge of the exhaust opening.

\section{Conclusion}

A difference between the reinforced exhaust slot system working with the workbench in the level of the bottom edge of the flange and in the level of bottom edge of the exhaust opening was observed. During capture efficiency measurements on the horizontal reinforced exhaust slot hood, the influence of the operating parameter (the ratio between the momentum flux supplied and the exhausted air flow) on the design of capture effective areas was evaluated. In both the cases the results of the measurement show that with increasing the value of the operating parameter $I$, the area of the high capture efficiency (greater than 80\%) becomes longer but its height becomes smaller. In reinforced modes with the workbench in the level of bottom edge of the exhaust opening the capture effective area near to the board of workbench is longer in comparison to the workbench in the level of the bottom edge of the flange.

\section{Acknowledgement}

The support of this research from the Czech Science Foundation project no. GA 101/09/H050 "Research into energy-saving devices to achieve comfort of the internal environment" and the BUT research project FSI-J-12-25 is gratefully acknowledged.

\section{References}

1. C. P. Aaberg, United States Patent \& Trademark Office, US patent 3401621(1968).

2. C. E. Hylgard, Int. Conf. on Air Distribution in Ventilated Spaces ROOMVENT (1987).

3. D. Gubler, REEXS Optimization of Operating and Design Parameters, PhD Thesis, Swiss Federal Institute of Technology, (2002).

4. J. Chysky and K. Hemzal, Ventilation and air conditioning - Design guidebook 31, Bolit, (1993).

5. S. Patocka, E. Janotkova and M. Pavelek, 12th Int. Conf. on Thermal Engineering and Thermogrammetry, p. 103 - 108.(2001). 